\title{
Modeling the Thermal Behavior of Permanent Magnet Synchronous Motors
}

\author{
A. LOTFI ${ }^{1}$, D. MARCSA 2 , Z. HORVATH ${ }^{3}$ \\ 1Széchenyi István University, Department of Mathematics and Computational Science, lotfi@sze.hu \\ ²Széchenyi István University, Department of Automation, marcsa@maxwell.sze.hu \\ ${ }^{3}$ Széchenyi István University, Department of Mathematics and Computational Science, horvathz@sze.hu
}

\begin{abstract}
The aim of this study is to present a thermal analysis of a permanent magnet synchronous machine based on finite element method. The developed model can be used to predict temperature distribution inside the studied motor during the rated operation. Electromagnetic computation is carried out with the aid of two $2 D$ finite-element (FE) simulations on the cross-section of the PM motor. To analyse the process of heat transfer in an electrical machine, empirical correlations are used to describe the convective heat transfer from the different surfaces of the PM motor. The heat transfer coefficient is determined using dimensionless numbers and Nusselt number. After the loss calculation, the temperatures of the machine are calculated by using $3 D$ finite element method. The results obtained by the model are compared with experimental results from testing the prototype electric motor.
\end{abstract}

\section{Introduction}

The main objective of our task is to develop a finite element model to analyse the thermal effects in electric machines during its various operating conditions. The application allows the predictions of simultaneous heat transfer in solid and fluid media with energy exchange between them and to determine the heat removal by natural convection from the machine surface. In electrical machines the permanent magnets and the insulation in the stator windings are sensitive to temperature variations, so a special attention must be paid to this part because the high temperature can affect the durability of the stator winding insulation and the efficiency of the permanent magnets. The prediction of the temperature distribution inside an electric motor is required at the machine design stage in order to control the temperature rise and to avoid overheating of the sensitive parts. The accuracy of the thermal model depends on the material properties and the knowledge of losses in electrical machine. In order to simplify the thermal model, the windings and the stator are treated as homogeneous medium with equivalent thermal parameters and the effective properties to characterize the thermal behaviour are calculated based on the volume-weighted average over all constituents. For heat transfer through the external surface of the machine, natural convection is considered. On the other hand the internal air gap is defined as solid and the effective conductivity to characterize the thermal behaviour of the air gap is calculated from empirical correlations. In the developed FEM model, total losses including winding loss and iron loss are simulated in Maxwell, ANSYS software and the estimated losses are then used as heat sources in the thermal model. This computation is made by coupling transient FEA thermal fields with the developed losses model. 
The proposed thermal model is implemented using the open source Feel++ software [8][9]. Two examples are presented to assess the accuracy of the developed coupled solvers and the numerical results are compared with the experimental ones, which are obtained from a prototype machine.

\section{Mathematical model and boundary conditions}

This model considers the transient heat transfer between all components of the PM motor including the air-gap [1] [2]. Heat transfer within the PM motor is modelled in Feel++ using the heat transfer analysis procedure. During the simulation the air gaps inside the machine were defined as a solid domain, the heat is mostly transferred by conduction. From the external walls of the motor housing, heat was released to the ambient by natural convection. The heat transfer transient model was solved in the entire domain consisting of the solid including the air gap in the form [3] [4] [5]:

$$
\rho c_{p} \frac{\partial T}{\partial t}=\nabla \cdot(-\lambda \nabla T)+Q, \quad \text { on } \Omega,
$$

where $\lambda$ is the thermal conductivity, $T$ is the temperature, $c_{p}$ specific heat capacity, $\rho$ the density and $Q$ is the heat source. On the external boundary, natural convection was considered:

$$
-\lambda \frac{\partial T}{\partial \vec{n}}=h\left(T-T_{0}\right), \quad \text { on } \partial \Omega
$$

where $\vec{n}$ is normal vector to the boundary, $h$ is heat transfer coefficient and $T_{0}$ is the ambient air temperature. To solve the heat transfer problem, we need to specify the temperature distribution at time zero:

$$
T=T_{0}, \quad \text { on } \Omega
$$

The accuracy of the thermal model depends on detailed definition of the geometry, the material properties (thermal conductivity, specific heat capacity,...) and the knowledge of losses in electrical machine.

\section{Determination of the thermal parameters}

In this study, all regions are considered homogenous and isotropic except stator and windings. For these regions, the thermal and physical properties are considered as anisotropic which means that properties change with 3-dimensional direction. The effective properties are calculated based on the volume-weighted average over all constituents. Afterwards, the model does not take into account the effect of temperature on thermal properties.

\subsection{Thermal Conductivity}

\subsubsection{Equivalent Thermal Conductivity of the stator}

The stator of an electrical machine is usually composed of a set of very thin metal laminations to reduce the eddy current losses caused by the magnetic flux alternation and each lamination being insulated from others by a thin layer of varnish. Therefore in this work we use the whole model of 
equivalent stator to simplify the stator. According to different materials and connections, the calculation of equivalent thermal conductivity coefficient is divided into two ways (Figure 1), which are series and parallel [6].

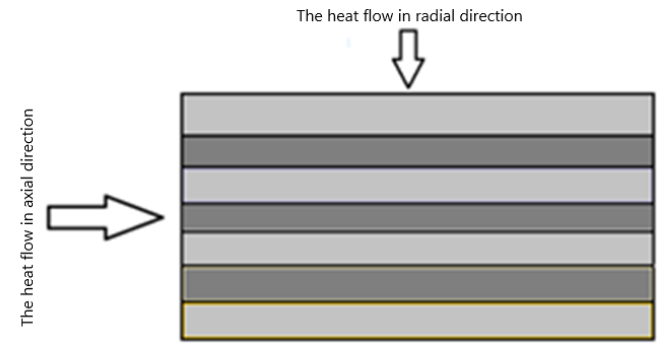

Fig.1. Model of radial and axial heat flow in laminated stator

- In the radial direction:

$$
\lambda_{\text {eq-radial }}=\lambda_{\text {iron }} n_{s}+\lambda_{\text {iso }}\left(1-n_{s}\right)
$$

where $n_{s}$ is the stacking factor and $\lambda_{\text {iron }}, \lambda_{\text {iso }}$ are the thermal conductivities of the iron and insulating respectively. The stacking factor represents the ratio of iron volume to the total volume of the stator. In this study the stacking factor is considered between 0.95 and 0.98 .

- In the axial direction:

1. In the case perfect contact:

Assuming perfect thermal contact at the layer interfaces, the equivalent thermal conductivity is

$$
\lambda_{\text {eq-axial }}=\frac{\lambda_{\text {iron }} \lambda_{\text {iso }}}{\lambda_{\text {iso }} n_{s}+\lambda_{\text {iron }}\left(1-n_{s}\right)}
$$

2. In the case no-perfect contact:

The equivalent thermal conductivity is

$$
\lambda_{\text {eq-axial }}=\frac{\lambda_{v} \lambda_{s z}}{\lambda_{\text {iso }} n_{s}+\lambda_{\text {iron }}\left(1-n_{s}\right)+(n-1) \frac{\lambda_{\text {iron }} \lambda_{\text {iso }} R_{C}}{H}}
$$

where $n$ is the total number of laminations, $H$ is the height of the stator and $R_{c}$ the thermal contact resistance [11]. In this study we use the thermal contact resistance data available in the literature.

\subsubsection{Equivalent Thermal Conductivity of Windings}

The material of stator windings contains conductors and insulators, such as copper, impregnating varnish and insulating varnish (Figure 2). 


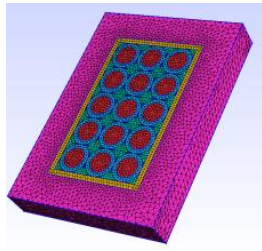

Fig.2. View of the stator windings

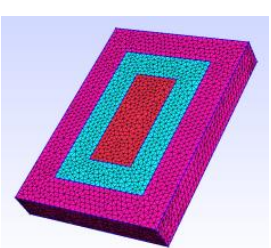

Fig.3. View of the simplified model of the stator windings

All conductors in the slot are replaced by an equivalent conductor, the equivalent conductor is shown in following Figure 3 and the equivalent cross section is equal to the sum of the cross sections of all conductors. And the space between the equivalent copper conductor and the stator is filled by an equivalent insulation which consists of the slot insulation, the equivalent air gap layer and the equivalent wire isolation.

In this case the equivalent thermal conductivity of the equivalent insulation is calculated in the axial and radial directions using the following formula:

1. In the radial direction:

The equivalent thermal conductivity is:

$$
\lambda_{\text {eq-radial }}=\frac{A_{\text {iso }}+A_{\text {lay }}+A_{\text {air }}}{\frac{A_{\text {iso }}}{\lambda_{\text {iso }}}+\frac{A_{\text {lay }}}{\lambda_{\text {lay }}}+\frac{A_{\text {air }}}{\lambda_{\text {air }}}}
$$

2. In the axial direction:

The equivalent thermal conductivity is:

$$
\lambda_{\text {eq-axial }}=\frac{A_{\text {iso }} \lambda_{\text {iso }}+A_{\text {lay }} \lambda_{\text {lay }}+A_{\text {air }} \lambda_{\text {air }}}{A_{\text {iso }}+A_{\text {lay }}+A_{\text {air }}}
$$

where $A_{i}, \lambda_{i}$ are the cross sectional area and conductivity of the constituent $i$.

\subsection{Specific Heat Capacity}

From the law of conservation of energy, the effective specific heat capacity is obtained:

$$
c_{p e q}=\sum_{i} c_{p i} \frac{v_{i}}{v}
$$

where $v_{i}, c_{p i}, i=1, \ldots, m$ are the volume fractions and the specific heat capacity of the constituent $i$.

\subsection{Effective Density:}

From the law of conservation of energy, the effective density is obtained by:

$$
\rho_{e q}=\sum_{i} \rho_{i} \frac{v_{i}}{v}
$$

where $v_{i}, \rho_{i}, i=1, \ldots, m$ are the volume fractions and the density of the constituent $i$. 


\subsection{Treatment of the Air Gap}

In the examples studied, the internal air gaps are totally enclosed. During the simulation the air gaps inside the machine were defined as a solid domain, the heat is mostly transferred by conduction. The air gap has higher thermal conductivity than ordinary air does. As the rotor rotate, the air motion in the machine cause turbulence in the air flow. In order to take into account the turbulent air flow in the air-gap, effective conductivity is used and is given by the following expression:

$$
\lambda_{\text {eq,air }}=0.069 \eta^{-2.9084} R_{e}^{0.461 \ln (3.3361 \eta)},
$$

where $R_{e}$ Reynolds number and $\eta$ the ration between the inner and outer air-gap diameter of the motor.

\subsection{Heat Transfer Coefficients for Free Convection Surfaces}

The heat transfer between the motor outer surface and the surrounding fluid can be characterized by the Nusselt number as a function other dimensionless parameters [7]:

\begin{tabular}{|c|c|c|c|}
\hline$N_{u}=\frac{h l}{\lambda}:$ & $R e=\frac{l v}{\mu}:$ & $\operatorname{Pr}=\frac{c_{p} \mu}{\lambda}:$ & $G r=\frac{\beta g \Delta T l^{3}}{\mu^{2}}:$ \\
\hline Nusselt number & Reynolds number & Prandtl number & Grashof number \\
\hline
\end{tabular}

where $l$ is the characteristic dimension of the body, $v$ is the velocity of the fluid, $\mu$ is the dynamic viscosity of the fluid, $\beta$ is the volumetric thermal expansion coefficient, $g$ is the gravity acceleration and $\Delta T$ is the temperature difference between surface and fluid flow . The heat transfer coefficient can be obtained and it is

$$
h=\frac{N_{u} \lambda}{l}, \text { where }\left\{\begin{array}{cc}
\left.N u=0.525(\operatorname{PrGr})^{0.25} \quad \text { (laminar if } 10^{4} \leq \operatorname{PrGr} \leq 10^{9}\right) \\
\left.N u=0.129(\operatorname{PrGr})^{0.33} \quad \text { (turbulent } 10^{9} \leq \operatorname{PrGr} \leq 10^{12}\right)
\end{array},\right.
$$

where $l$ is the outer diameter of the motor.

\section{Electromagnetic Losses}

The losses of an electric machine consist of: stator iron losses, stator copper losses, rotor iron losses and permanent magnet loss. The mechanical losses are assumed to be negligible in the studied machine. Electromagnetic losses consist of two main components:

I. Winding copper losses:

Copper losses result from the electrical resistance in the coils of a motor and the current passing through it which is dissipated as heat.

$$
P_{C u}=3 R_{C u} I^{2},
$$

where $I$ is the current flowing through the coils and $R_{C u}$ is the electric coil resistances. 
II. Core losses:

The core loss of electric machine with sinusoidal excitation is commonly computed based on loss separation, which breaks the total core loss into hysteresis loss and eddy-current loss components:

$$
P=P_{h}+P_{e}=k_{h} \cdot f \cdot B_{m}{ }^{2}+k_{e}\left(f \cdot B_{m}\right)^{2},
$$

where $k_{e}$ is the Eddy current loss constant, $k_{h}$ is the hysteresis loss constant, $B_{m}$ is the maximum flux density and $f$ is the frequency.

Electromagnetic computation is carried out with the aid of two 2D finite-element (FE) simulations on the cross-section of the PM motor using the Ansys Maxwell. The electromagnetic losses are used as an input to the numerical thermal model to find the temperature of the motor.

\section{Numerical Simulations}

\subsection{The first example: BMW C1 $11 \mathrm{~kW}$ electric motor}

\subsubsection{Geometry and mesh of the Analysed Motor}

As shown in Fig.4, the electric motor model has a very complicated geometry. Obviously, it is not possible to perform simulation on the entire PM motor, due to the large number of volumes and calculations required. Therefore, a part of the PM motor consisting of each part (front cover, stator core, stator windings, rotor, permanent magnets, shaft, external housing and the air-gap between these components are modelled for this study as shown on the Fig.4. and Fig.5. shows a detailed view of the main components of the modelled electric motor.

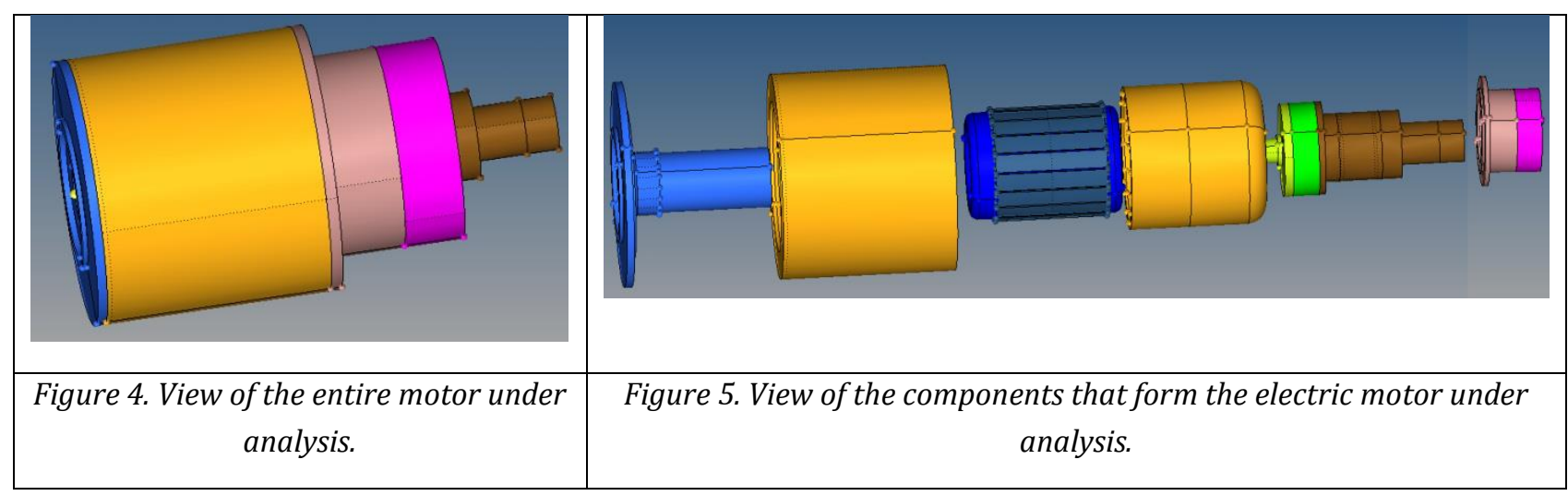

Model detail includes; (1) the front cover, (2) and (5) the external housing geometry, (3) the stator core geometry including slot detail and the stator windings, (4) the rotor geometry including permanent magnets and shaft. In order to simplify the model, the winding region was modelled as a solid section and the end winding region was modelled as a torus. This assumption made this motor element easier to mesh. 

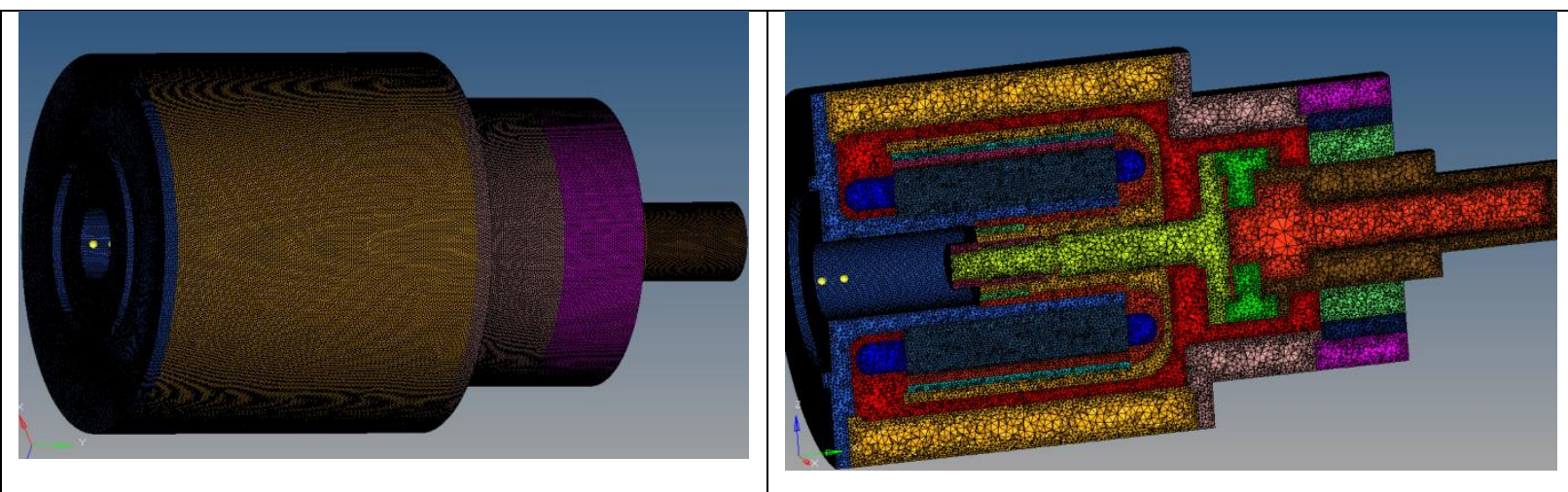

Figure 6. A general view of the final mesh.

As shown in Fig.6, the mesh for the motor and the air-gap was created based on tetrahedral elements, as these are the only elements capable of meshing that domain. This grid has approximately 4000000 cells.

\subsubsection{Losses in BMW C1 motor}

First, a 2D magnetic FE model of the investigated machine is simulated in ANSYS software in order to obtain the magnetic field in the active parts of the PM motor. In addition, the copper losses and the magnetic core losses are modelled based on the results from the finite element analysis. The computed copper and iron losses are presented in Table 1 for current $100 \mathrm{~A}$ and angular velocity $2000 \mathrm{rpm}$. Due to periodicity of the motor, only the half of the motor is analyzed in order to reduce the computation time. Figures 7-8 show the stator core loss and the rotor core loss. In this study, the heat source is assumed to be uniformly distributed within the generating components.

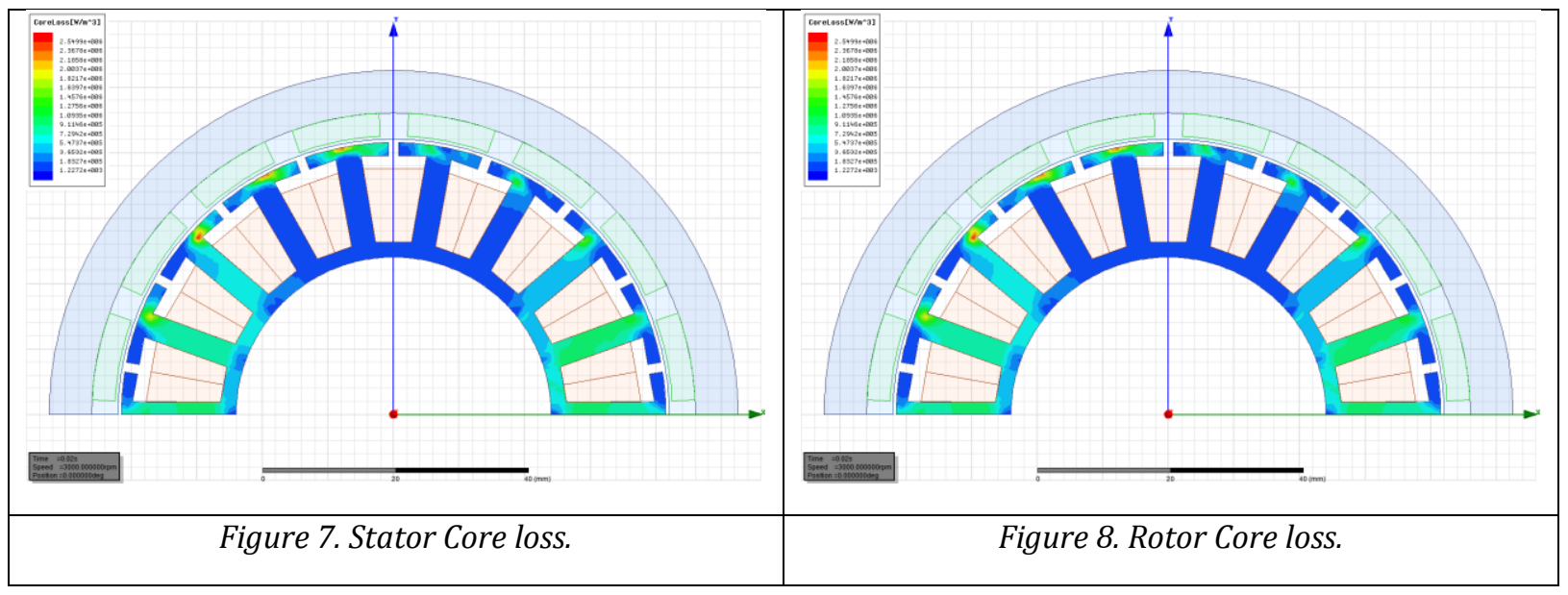

\begin{tabular}{|l|l|}
\hline Copper losses in stator windings & 162.6 \\
\hline Stator iron loss & 36.41 \\
\hline Rotor iron loss & 41.58 \\
\hline Permanent magnet Loss & 02.55 \\
\hline
\end{tabular}

Table 1. The heat source in the PM motor $(W)$ 


\subsubsection{Results}

According to the model mentioned above, a transient 3D FE thermal were carried out using the FEEL++ library and it was executed on 30 processors. Figs. 9 (a)(b)(c)(d) show the temperature distribution of the motor at time $t=1600 \mathrm{~s}$.

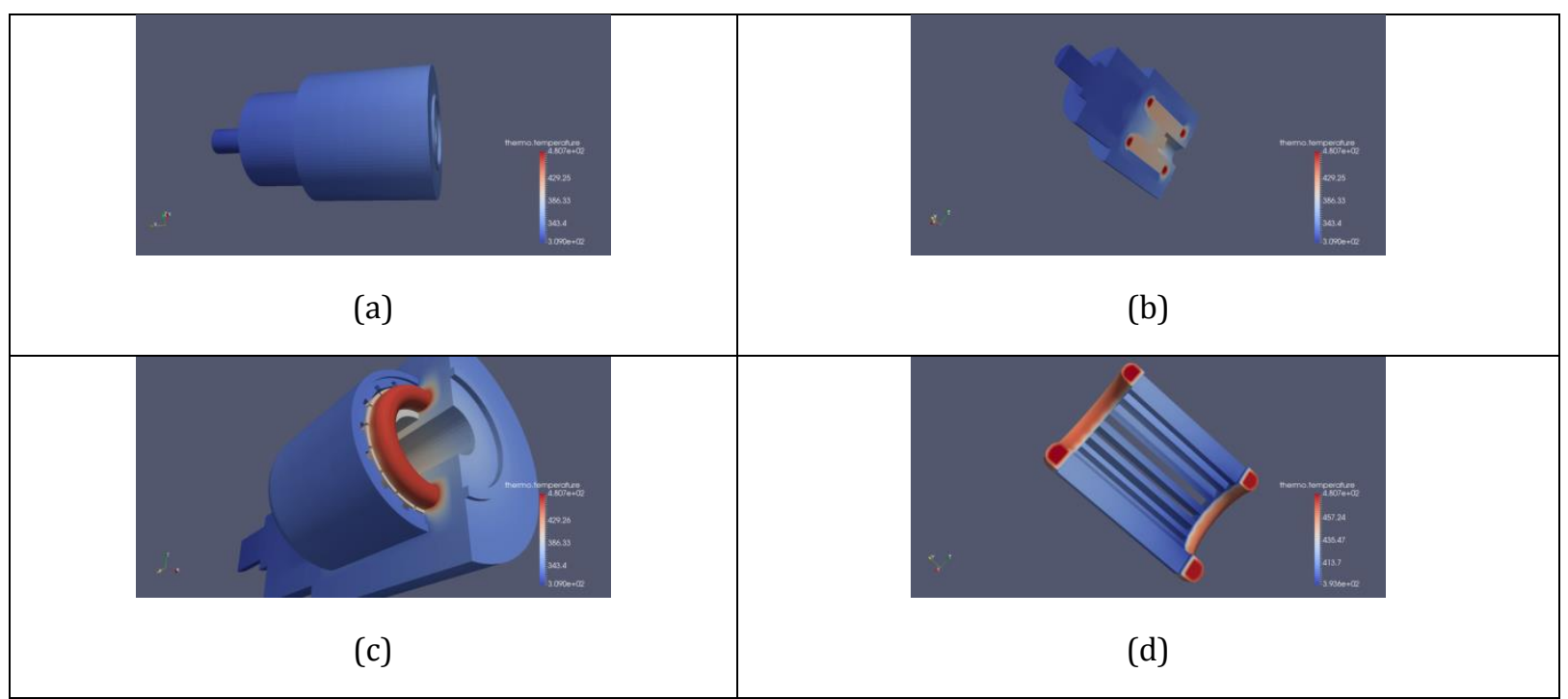

Figure. 9 Contours of temperature of the electric motor.

\subsection{The second example: Toyota Prius 2004 electric motor}

\subsubsection{Geometry and mesh of the Analysed Motor:}

In this study we perform numerical computation for the heat transfer in Toyota Prius 2004 electric motor (see fig.10.).

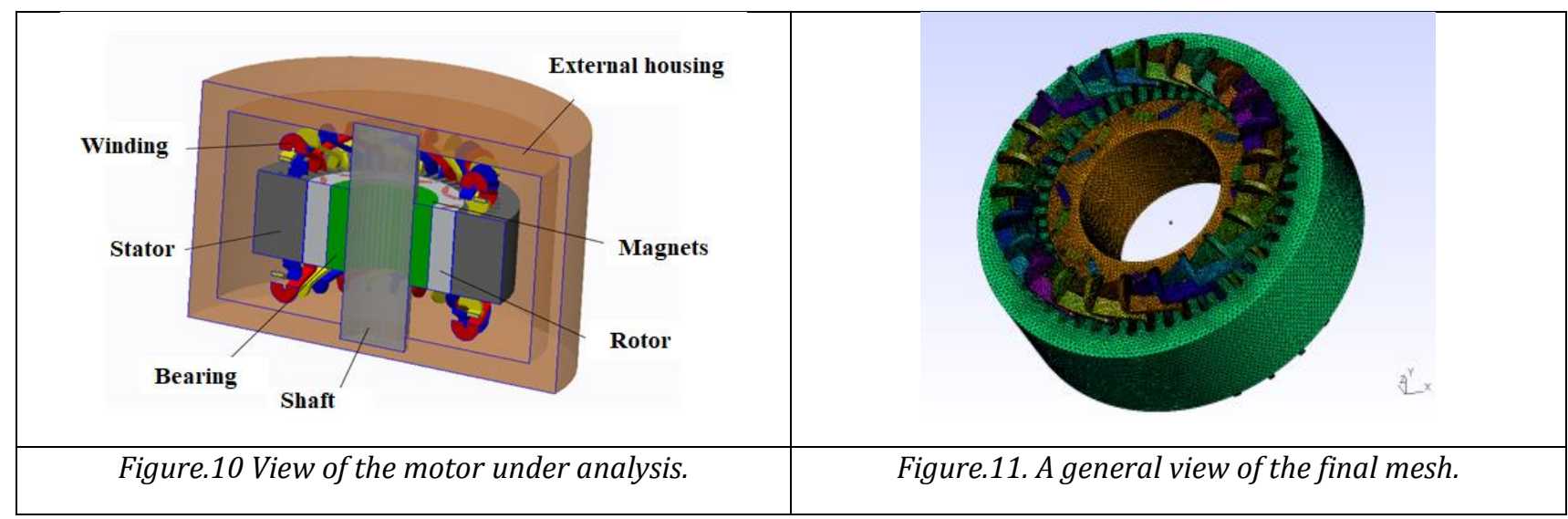

The mesh for the motor and the air-gap was created based on tetrahedral elements, as these are the only elements capable of meshing that domain. This grid has approximately 7500000 cells and Fig. 11 shows the mesh of the critical parts of the electric machine such the winding, stator, the rotor and the magnets. 


\subsubsection{Losses in Toyota Prius 2004 electric motor}

The computed copper and iron losses are presented in Table 2 for current 100 A and angular velocity $2000 \mathrm{rpm}$.

\begin{tabular}{|l|l|}
\hline Copper losses in stator windings & 436.2 \\
\hline Stator iron loss & 345.1 \\
\hline Rotor iron loss & 26.1 \\
\hline Permanent magnet Loss & 1.9 \\
\hline
\end{tabular}

Table 2 The heat source in the PM motor (W)

Due to periodicity of the cross section of the motor, only the eighth of the motor is analyzed. The loss calculation results of electromagnetic computation can be seen in Fig. 12.

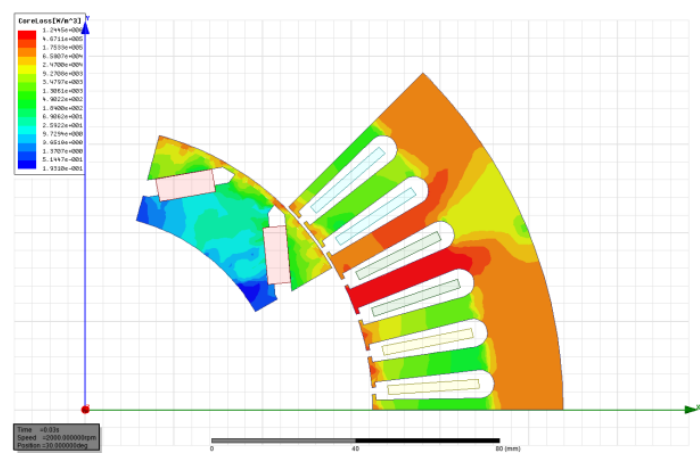

Figure 12 The stator and rotor core losses.

\subsubsection{Results}

According to the model mentioned above, a transient 3D FE thermal were carried out using the FEEL++ library and it was executed on 60 processors. Figs.13.(a)(b)(c)(d) show the temperature distribution of different parts of PM motor at time $t=500 \mathrm{~s}$.

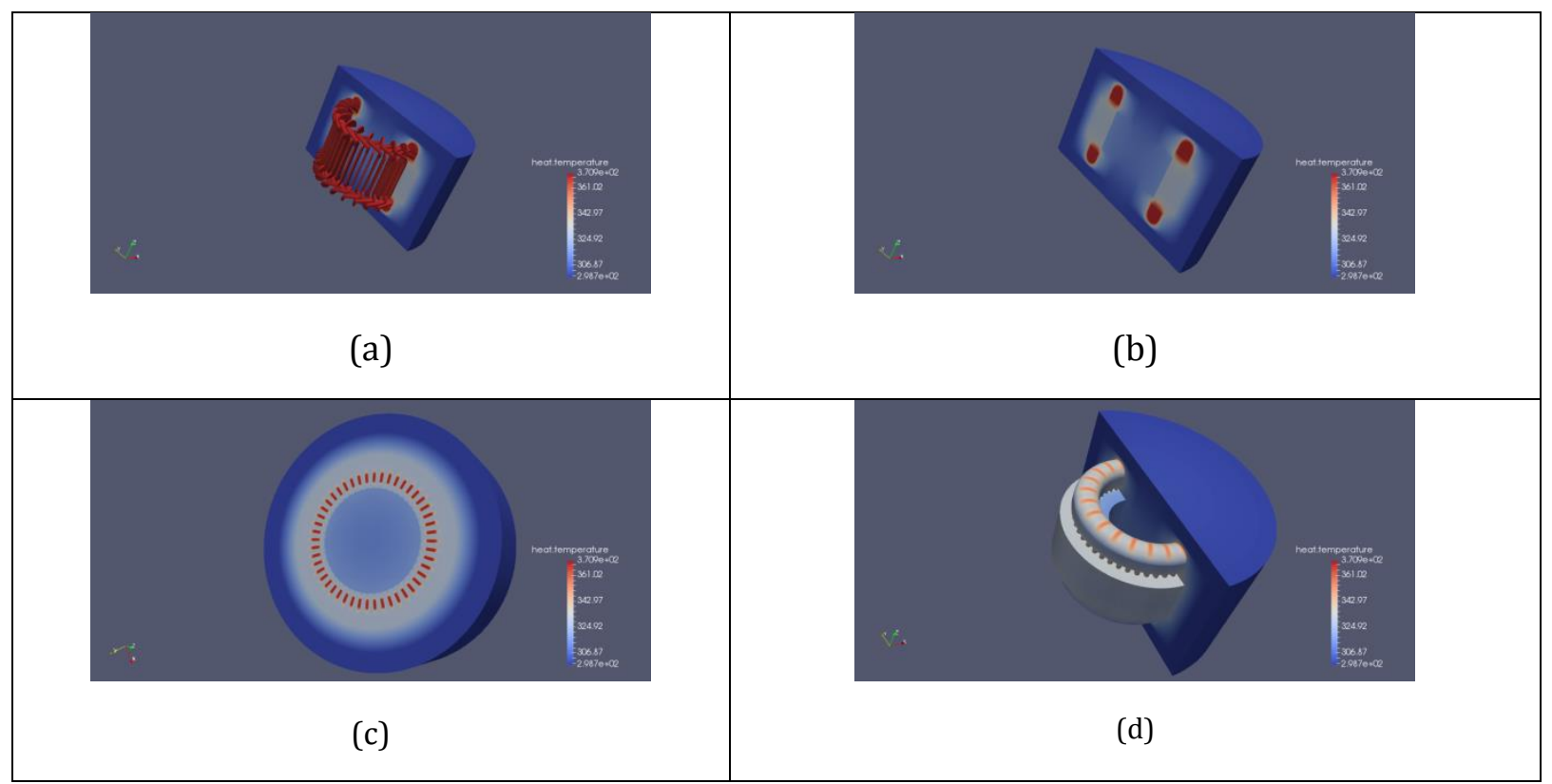

Figure 13 Contours of temperature of the electric motor. 


\section{Comparison of Simulated and Experimental Results}

The measurements were performed on the BMW C1 $11 \mathrm{~kW}$ motor presented in Fig. 14. The temperature was measured using a thermocouple type PT100 in contact with the surface of the tested motor. Twenty four PT-100 temperature sensors where placed on the permanent magnet motor before the test, as shown in Fig. 15. These temperatures were later used to validate the numerical model [10].

The stator coil is supplied with a constant current of 100A for duration of 1800 seconds and then the current is turned off; the rotor was locked in a stand still position. The temperature rise was exclusively caused by the resistive heating of the winding. The main goal of the experiment was to reach a steady-state condition.

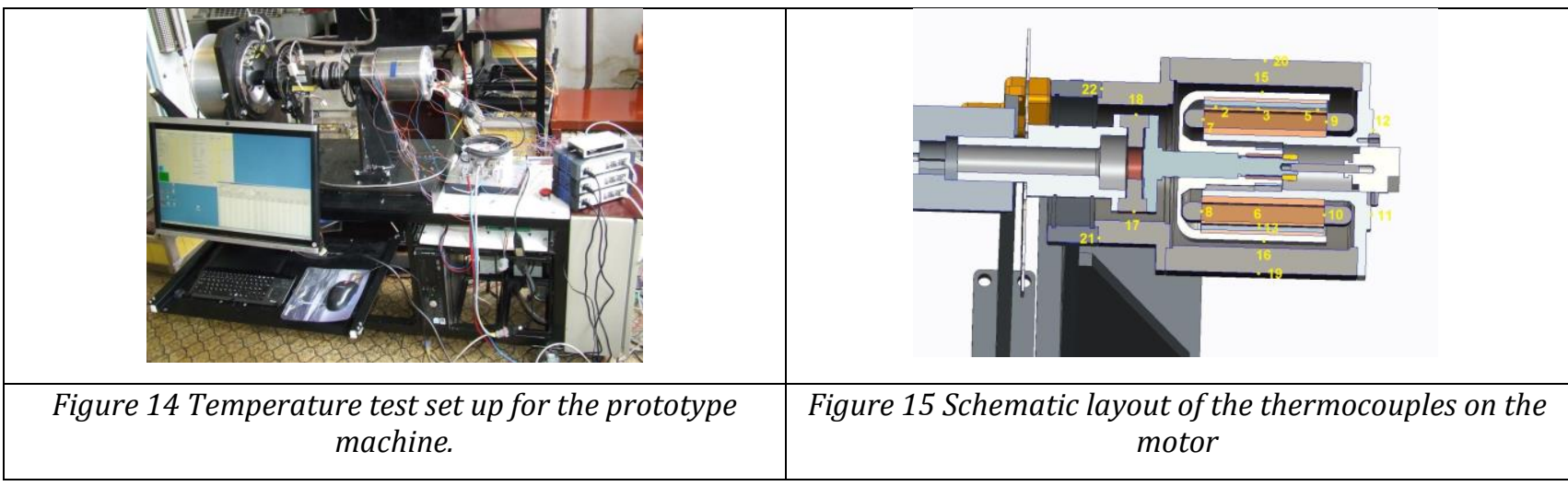

During the temperature test, the most significant heat source in the tested motor is copper losses, due to the electric resistance in the stator coils. The heat generation model utilizes the measured $V(t)$ voltage and the measured $\mathrm{I}(\mathrm{t})$ current to determine the motor losses from the winding and these losses are then used as an input to the numerical thermal model to find the temperature of the motor and the other losses are ignored. Fig.16. shows the experimental value of Joule losses variation with time.

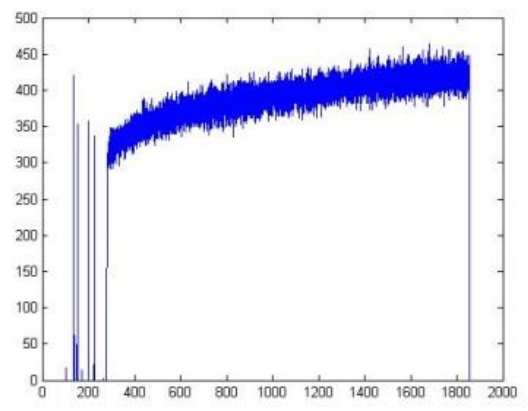

Figure 16 Experimental value of Joule losses variation with time.

We solve the problem by taking the ambient temperature $22 \mathrm{C}$ of the motor as the initial temperature. Fig. 17 shows a comparison of the simulated and measured temperature variation obtained by a few thermocouples [10] 
The simulated temperatures are very accurate for locations in the motor obtained by thermocouples 1 , $2,3,4,5,6,9,10,11,12$, but the results from the model are not in good agreement with the results obtained by the remaining thermocouples. However, the reasons for the discrepancy between transient temperature simulation and measurement need to be explained. The difference transient

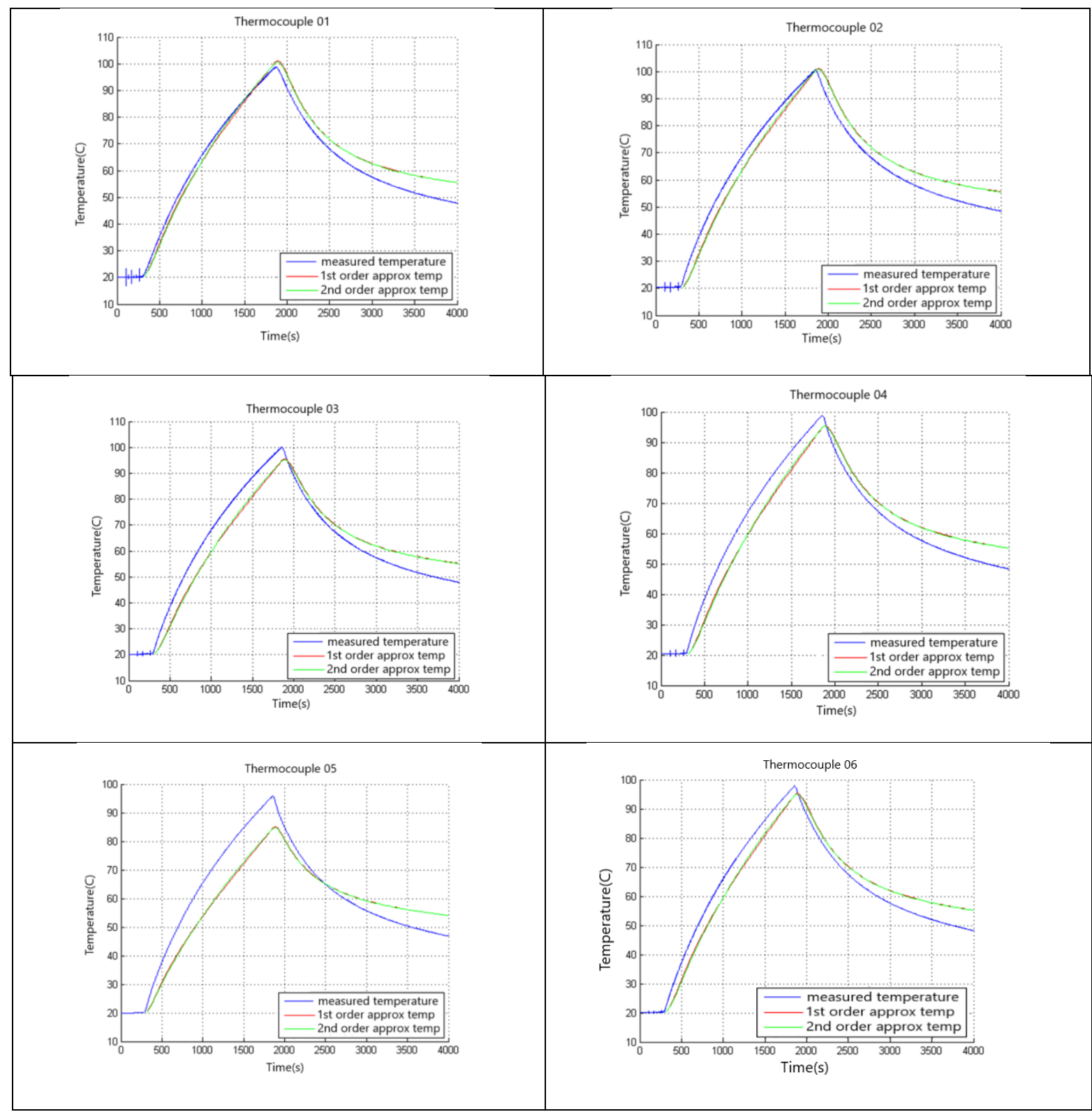

Figure 17 Comparison of the FE simulated and measured temperature variation at different position of PM motor.

temperature simulation and the results of experiments can be attributed to the followings: the glue layers between the thermocouples and the prototype motor can decrease heat transfer, the material properties were assumed to be independent of temperature and the mechanical losses were are neglected. 


\section{Conclusions}

The developed method, electromagnetic field and thermal linked analysis, gives the possibility to evaluate magnetic field intensity, the core losses in the material and the temperature distribution of PM motor for different currents and for different geometrical parameters. The developed model enables to predict temperature distribution with good accuracy of the critical parts of the electric machine such the winding, the rotor and the magnets without using the time-consuming CFD simulations. Convection heat-transfer problems are treated with dimensionless numbers and empirical correlations are used to determine heat-transfer coefficient.

\section{Acknowledgments}

This work was supported by the FIEK program (Center for cooperation between higher education and the industries at the Széchenyi István University, GINOP-2.3.4-15-2016-00003).

\section{References}

[1] J. Gieras - R. Wang - M. Kamper (2008) Axial Flux Permanent Magnet Brushless Machines. Springer.

[2] P. H. Mellor - D. Roberts - D. R. Turner (1991) Lumped parameter thermal model for electrical machines of TEFC design. IEE Proceedings-B, 138 (5) pp. 205-218.

[3] A. Arkkio - T. Jokinen - E. Lantto (2005) Induction and permanent-magnet synchronous machines for high-speed applications. in Proc. 8th ICEMS, Sep. 27-29, 2 vol. 2, pp. 871-876.

[4] O. Aglén - Å. Anderson (2003) Thermal analysis of a high-speed generator. in Proc. 38th IAS annual meeting, Oct. 12-16, 2003, pp. 547-554.

[5] D.A Howey - P.R.N. Childs - A.S. Holmes (2012) Air-gap convection in rotating electrical machines. IEEE Transactions on Industrial Electronics. 59. pp. 1367-1375.

[6] J. Gyselinck - P. Dular - N. Sadowski - P. Kuo-Peng - R. V. Sabariego (2010) Homogenization of Form-Wound Windings in Frequency and Time Domain Finite-Element Modeling of Electrical Machines. IEEE Transactions on Magnetics. 46 pp. 2852-2855.

[7] F. P. Incropera - D. P. DeWitt (2000) Fundamentals of Heat and Mass Transfer (4th ed.). New York: Wiley. p. 493.

[8] The Feel++ Book: https://book.feelpp.org/.

[9] Solving PDEs with Feel++: (http://calcul.math.cnrs.fr/Documents/Ecoles/2017/FEM/lecture.feelpp.slides.pdf).

[10] Kuslits M. "BMW C1 motor rövidzárási hőmérsékletmérése: Mérési jegyzốkönyv", 2014. (in Hungarian language)

[11] Gy. Gróf (1999) Hőközlés. ideiglenes jegyzet, Budapest. (in Hungarian language) 